\title{
0 impacto potencial da atual estrutura de financiamento da gestão descentralizada do SU S na redução de desigualdades regionais
}

\author{
The potential impact of the current financing \\ structure of the SUS decentralized management \\ in the reduction of local inequalities
}

Fernando $M$ artins Júnior 1

Alexandre M ont'Alverne Silva 2

Jorge Solla 3

Nelson Rodrigues dos Santos 4

1 M édico. Coordenador de Regulação das Ações e Serviços de Saúde e Secretário Substituto de Saúde do Estado do Rio Grande do Sul. 2 Coordenador de Políticas de Saúde da Secretaria da Saúde do Estado do Ceará 3 Secretário M unicipal da Saúde de Vitória da Conquista (BA)

4 Coordenador do Conselho Nacional de Saúde.
$C \& S C$ As atuais modalidades de financiamento da gestão descentralizada do Sistema Ú nico de Saúde (valores per capita nacionais, incentivos financeiros) tem potencial para reduzir desigual dades inter-regionais? Que aspectos devem ser revistos e/ou aperfeiçoados?

FMJr Sem dúvida, a adoção de um per capita para o Piso da Atenção Básica, previsto na N OB/ 96, foi um dos grandes incentivadores da ampliação da municipalização da saúde e, conseqüentemente, responsável pela ampliação da cobertura do SUS. Até então só havia possibilidade de recebimento de recursos pel os municípios através da produção de serviços, o que não favorecia a ampliação da rede, pois era necessário produção anterior para a garantia de recebimento de recursos.

Entretanto, mesmo reconhecendo a importância, em determinado momento, da adoção desse critério, entendo que já poderíamos ter avançado na direção do cumprimento do art. 35 da lei 8.080/90, aliando ao per capita outros critérios que permitissem reconhecer as peculiaridades locais. A princípio a lógica foi de disseminar a cobertura mínima, que hoje já não é suficiente para as necessidades do SU S, sendo preciso a instituição de outros critérios que reconheçam as diversidades regionais.

Quanto aos incentivos financeiros, esses têm sido utilizados para a indução de estratégias de atenção pensadas de forma centraliza- da, sem reconhecer a possibilidade de remunerar iniciativas locais que muitas vezes têm se mostrado exitosas na qualificação e ampliação do acesso. Parece-me necessário que se comece a pensar em incentivar políticas e propostas de organização de sistemas de saúde e não programas verticais que, na maioria das vezes, desconhecem as características locais.

AM AS Houve na realidade dois passos importantes na redução das desi gual dades entre estados e municípios: O PAB, sobretudo o fixo, e uma emenda ao orçamento da União, salvo engano em 2000, puxada pela bancada da Bahia, que al ocou recursos adicionais nos tetos estaduais inversamente ao per capita existente. 0 PAB ampliado, e sobretudo o per capita para o M 1 (primeiro nível da média complexidade) teria esse papel, mas o nível irrisório do PAB ampliado desestimulou os municípios a assumirem a condição de gestão. Por outro lado, o FAEC reforçou as desigualdades, e o que é pior, além de reforçar, ocultou as desigualdades, pois ao contrário dos tetos, só o M S sabe quanto vai para cada Estado ou município. Já os incentivos, estes viraram uma colcha de retal hos tão complexa que mesmo o MS tem dificuldade de saber quanto vai para cada local. Acho que há uma grande diferença entre o incentivo a uma estratégia estruturante como o PSFque somente por marketing mantém a "grife" com o nome programa, e os incentivos outros para cada 
ação. Além disso, a falta de atualização do PAB, a criação de inúmeros subtetos, a falta de atualização dos valores das tabelas e outras iniciativas voltaram a concentrar recursos no nível federal com prejuízo tanto da redução das desigualdades, mas sobretudo da transparência. Vale lembrar que a EC 29 pode reforçar desigualdades, pois ao reduzir o percentual de gasto federal na saúde, e aumentar o gasto estadual, já que estados têm capacidade muito distinta de arrecadar, porque a riqueza nacional está distribuída de forma muito desigual, na realidade, reforça as desigualdades

JS Consideramos que a implantação de novas modalidades de financiamento, superando parcialmente o repasse de recursos com base na produção de serviços condicionada pela série histórica e capacidade instalada cadastrada, cria possibilidades para redução de desigualdades intra e inter-regionais. Contudo, estas ainda estão limitadas ao campo da atenção básica. A extensão para os patamares iniciais da média complexidade ambulatorial definidos pela NOAS ainda não tiveram efetividade em função do atraso para a habilitação de municípios pela NOAS. Acredito que ampliar a utilização de valores per capita nacionais para toda a média complexidade ambulatorial seria um avanço significativo no estágio atual. Cabe ressaltar que o cálculo de valores per capita a partir de médias nacionais cria limitações para sua implantação, na medida em que representariam uma ampliação de recursos em determinados municípios e regiões e uma retração em outros, especialmente nos grandes centros urbanos. Para tanto, seriam necessários ajustes, como os que foram feitos na ocasião de implantação do $\mathrm{PAB}$, quando se optou por uma faixa de valores de $R \$ 10,00$ a $R \$ 18,00$. É bom lembrar que o impulso dado com a implantação do PAB em 1998 representou uma melhoria do financiamento da atenção básica na maioria dos municípios brasileiros. $\mathrm{M}$ as, o que se custeava com $\mathrm{R} \$ 10,00$ em 1998 era muito mais do que é possível hoje de ser pago com estes valores; se já era pouco em 1998 (lembrar que o valor estudado para 1996 seria de $\mathrm{R} \$ 12,00)$, quatro anos depois sem correção levou a um progressivo desfinanciamento. Os valores per capita não podem ficar congelados! Quanto aos incentivos financeiros, acho uma política que pode obter sucesso, como tem sido evidenciado em certa medida, especialmente no tocante à implantação do Programa de Saúde da Família. Acho legítimo que o Ministério da
Saúde pratique políticas de indução financeira. Todavia, diversos aspectos precisam de reformulação urgente. Entre eles destacam-se: a) o valor do incentivo - valores muito baixos não são estímulos reais para a implantação adequada das ações, levando a distorções em muitos municípios, onde se pratica um rebaixamento das ações propostas, redução de carga horária de profissionais e outras maneiras de viabilizar o recebimento do recurso sem viabilizar os objetivos propostos; e b) o comprometimento de financiamento dos três níveis - propostas como a negociada para a assistência farmacêutica com estabel ecimento de contrapartidas estaduais e municipais poderiam ser praticadas para as outras políticas de incentivo financeiro. NR Já teve mais e está no fim. As atuais modalidades, incluindo os repasses federais, esgotaram-se. Diretrizes para novas modalidades

C\&SC Que papel as instâncias colegiadas de formulação e gestão das políticas do SUS (Comissões Intergestoras e Consel hos de Saúde) vêm desempenhando efetivamente no processo de formulação das inovações no financiamento da gestão descentralizada?

FM Jr Acredito que tanto as Comissões Intergestores como os Conselhos de Saúde já foram bem mais atuantes em relação à formulação de políticas de saúde. Hoje, com exceção de alguns estados em que o processo de descentralização e participação popular conseguiu avançar, o que se tem visto são Bipartites voltadas ao interesse de gestores de saúde e não da necessidade dos usuários e conselhos desarticulados e com dificuldade de formulação de políticas.

No cenário nacional o que se observa é um completo desrespeito do gestor com os órgãos de Controle Social e de Pactuação. O Conselho Nacional de Saúde vem sendo desconhecido pelo ministério quando se trata de discutir a formulação de políticas, e a Tripartite tem-se tornado cada vez mais um fórum de apresentação de propostas do ministério, as quais mesmo sem aprovação dos gestores têm sido implementadas de forma unilateral.

AMAS O CNS, através da Cofin, tem acompanhado algumas questões ligadas ao financiamento, sobretudo o montante do Orçamento Federal, o desempenho por programa, a regulamentação da EC 29, mas não tem discutido a distribuição regional nem a execução descentralizada.

A Tripartite, e mesmo o CONASS e o CO- 
N ASSEM S não têm conseguido formular. $\mathrm{Na}$ $\mathrm{CIT}$, geralmente o MS, além de fazer a pauta, como se arvora em "dono do dinheiro", chega muitas vezes apenas para comunicar portarias já no prelo. E muitas vezes tem implantado medidas sem a concordância dos demais parceiros. A "radicalização" da gestão plena, com a obrigatoriedade de municípios em Gestão Plena assumirem a gestão da alta complexidade, por um lado pulveriza recursos, mas, na verdade, os concentra, pois cria subtetos que se 0 município não gasta ficam retidos, e se ultrapassa, então, tem de usar recursos da média complexidade. Ora, na prática, voltamos à gestão incipiente, pois o município apenas autoriza um teto que fica no governo federal.

JS A Comissão Intergestores Tripartite tem sido palco de debates sobre essas questões, inclusive nos últimos dois anos com a discussão sobre a N OAS. Acredito que o Conselho N acional de Saúde precisa ser mais ouvido neste debate. Grandes mudanças no financiamento da gestão descentralizada encontram resistência forte especialmente por parte das gestões estaduais. É exemplar o debate acerca da PPI, quando foi proposto que esta estabelecesse não apenas a alocação dos recursos federais, como também dos estaduais e dos municipais. I sso foi inviabilizado pela posição dos secretários estaduais de saúde. Na maioria absoluta dos estados não existem repasses financeiros de recursos do Tesouro estadual para financiar a assistência à saúde nos municípios. Os recursos humanos contratados pelas SES que estavam cedidos aos municípios vão progressivamente se afastando e aposentando sem serem repostos. Em casos extremos, como o da Bahia, todo o pessoal cedido teve perdas até superior a metade de seus vencimentos, o que demandou que os municípios tivessem de assumir complementações e em al guns municípios foram retirados para cobrir lacunas de pessoal em serviços que estejam ainda sob gerência estadual. Essas dificuldades de relação entre os níveis de governo dificilmente serão superadas exclusivamente pelas comissões intergestores, demandando um papel mais ativo dos conselhos de saúde.

NR Até agora, insuficiente para superar e/ou contornar a hegemonia dos convênios, da remuneração por produção e do "fundo a fundo" induzido para reprodução da remuneração por produção e para o fracionamento dos gastos por programas e atividades padronizadas nacionalmente e incentivadas localmente. OS conselhos de Saúde só recentemente iniciaram priorização da sua atribuição de formulação de estratégias. Vide Conselho $\mathrm{N}$ acional de Saúde através do site <http//conselho.saúde.gov.br>

C\&SC É possível avaliar o impacto das estratégias para a descentralização da gestão do sistema, implementadas no âmbito das Normas O peracionais Básicas do SU S, sobre a situação da saúde local? Que mudanças podem ser observadas ou evidenciadas?

FM Jr O tema da avaliação em saúde é uma das principais discussões que devem ser feitas no próximo período. Apesar de termos um processo de implantação do SU S em substituição ao antigo "modelo do Inamps", a avaliação continua sendo feita apenas em cima de procedimentos "médicos", levando em conta o quantitativo produzido e o valor gasto, sem incluir análises de custos desses procedimentos e, principalmente, não medindo impacto sobre a saúde da população, qualidade e satisfação dos usuários, questão imprescindível para um sistema que tem entre suas diretrizes o controle social.

Entretanto, mesmo com a dificuldade de formulação de uma avaliação embasada em critérios cientificamente testados, é inegável que houve uma grande ampliação do acesso nos últimos anos, principalmente devido à municipalização da saúde.

AMAS As NOBs têm sido, na realidade, um caminhar lento no processo de descentralização, a meu ver, positivo. H ouve redução de desigualdades, e onde a gestão local é comprome tida com mudanças, elas ocorrem. Onde os estados atuam catalisando as iniciativas municipais, há um processo mais amplo de mudanças. Onde os estados não atuam, acontecem ilhas de prosperidade. Aliás, este é um problema que somente a atuação dos estados pode atenuar: o surgimento de uma "casta" de municípios em gestão plena, que consegue mais recursos, e, com uma boa gestão, avança na mudança, enquanto outros, com lideranças políticas atrasadas, e sem o Estado para exercer o papel de atividade suplementar ao município, perdura com situações de saúde deprimente.

No N ordeste é flagrante a melhoria da situação de saúde nos municípios onde há gestores comprometidos, mas também é flagrante 0 aumento das dificuldades pela nova concentração de recursos, conforme explicado nas questões 1 e 3. As N OAS, por sua vez, tiveram papel importante no reforço da atividade planejadora dos estados, e na indução de uma regionali- 
zação, mas os aspectos já mencionados referentes ao financiamento (falta de atualização dos valores, e concentração de recursos no $\mathrm{MS}$ ) impediram sua Implantação. PABA (Piso de Atenção Básica Ampliada) de $R \$ 0,50$ é brincadeira de mau gosto.

JS Considero, como já comentei anteriormente, que a implantação da N O B/96 com a introdução do PAB e a entrada massiva dos municípios na gestão do SUS, mesmo que na absoluta maioria apenas no âmbito da atenção básica, teve um impacto enorme na ampliação da oferta de serviços e uma melhoria do acesso da população à rede SUS. Em muitos municípios, serviços foram implantados, profissionais foram contratados, ações fundamentais foram desenvolvidas ou tiveram sua cobertura ampliada. Além de impactos rel acionados à ampliação da atenção básica, pode-se observar diversos municípios em gestão plena do sistema municipal de saúde apresentando mudanças significativas na ampliação do acesso e da oferta dos outros níveis de atenção, na correção de distorções anteriormente existentes (fraudes, duplas cobranças, etc.), na implantação de novas modalidades assistenciais, na melhoria da articulação entre serviços e níveis de atenção, na implantação de ações de regulação, controle, avaliação e auditoria, entre outras áreas.

NR É possível, mesmo que por estimativas. Significativa el evação da cobertura da aten ção básica e início do controle de desperdícios na média complexidade. Elevação do acesso na $A B$ e monos na $M A C$.

$C \& S C$ A gestão descentralizada do SU S é uma realidade nacional? 0 que poderia ser apontado como a principal mudança nas relações intergovernamentais desencadeada pelo processo de descentralização da gestão do sistema de saúde?

FMJr Sem dúvida, a principal modificação está na responsabilização dos gestores locais e estaduais com as condições de saúde dos cidadãos de seus municípios e estados. Entretanto, o gestor federal continua exercendo, de forma importante, um papel de tutela sobre as políti- cas locais e regionais de saúde, o que inibe a ação dos demais entes federados, impedindo um processo de descentralização real, baseado não apenas na transferência da execução de tarefas planejadas centralmente, mas principalmente na autonomia de cada ente federado.

AM AS Sim, embora com todas as dificuldades mencionadas. A transferência dos recursos fundo a fundo com base populacional muda radicalmente o que havia inicialmente, e o que a atual gestão recriou: um monte de critérios que têm de ser discutidos um a um com cada pedaço do ministério, é as chamadas transferências "convênio-like". Os secretários voltaram a ser gerentes de contas, onde sobra em uma (e aí fica para o FAEC), e falta noutra, sem que elas possam se comunicar entre si.

JS A pesar das dificuldades que ainda existem, a área de saúde, sem sombra de dúvida, foi a que mais avançou nas relações intergovernamentais. N enhuma outra criou comissões ou câmaras intergestores como as existentes no SUS. A descentral ização da gestão do SU S éuma realidade nacional, mesmo apresentando disparidades regionais. Existem ainda comissões intergestoras Bipartites, em que a disparidade de poder entre a representação do Estado e as municipais leva a que as decisões aprovadas sejam sempre, ou na maioria absoluta das vezes, aquelas defendidas pela Secretaria Estadual. Já tivemos situações em que o governo estadual chegou a organizar e fazer campanha para eleger uma chapa de secretários municipais de saúde de sua "confiança" para a direção do Consel ho Estadual de Secretários M unicipais de Saúde com vistas principalmente a ter sob controle a representação dos municípios na Bipartite.

NR É mais um processo em andamento do que uma realidade, no sentido da gestão de sistema loco-regional: a hegemonia do financiamento e da indução do perfil da oferta de serviços encontra-se ainda com a U nião eas U nidades da Federação mais desenvolvidas. A principal mudança encontra-se no processo de deslocamento de decisões para o COSEM s e $\mathrm{ClBS}$ 